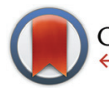

CrossMark

\& click for updates

Cite this: Analyst, 2015, 140, 6477

Received 17th June 2015,

Accepted 20th July 2015

DOI: $10.1039 /$ c5an01218j

www.rsc.org/analyst

\section{Regal electrochemistry: British 5 pence coins provide useful metallic macroelectrode substrates $\uparrow$}

\author{
Fang Tan, Jamie P. Smith, Dimitrios K. Kampouris, Joanna Kamieniak and \\ Craig E. Banks*
}

The utilisation of British Currency (GBP) as an electrode substrate is demonstrated for the first time. Termed Regal electrochemistry, a 5 pence (5p) coin (GBP) is electrically wired using a bespoke electrochemical cell and is electrochemically characterised using the outer-sphere redox probe hexaammineruthenium(III) chloride. The electroanalytical utility of the $5 p$ coin electrode is demonstrated towards the novel, proof-of-concept sensing of lead(II) ions using square-wave voltammetry in model buffer solutions over the linear

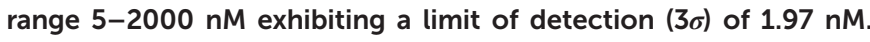
Interestingly, the actual cost of the electrode is 2.5 pence (GBP) since both sides of the coins can be utilised and provide a cheap yet reproducible and disposable metallic electrode substrate that is electrochemically useful.

\section{Introduction}

Electroanalysts are always searching for new materials that are both economical and electroanalytically useful. To this end, a wide array of different materials are explored in the hope of finding the next low cost, reliable sensor that, if applicable, is useable in-the-field (disposable) and exhibits useful electroanalytical performances towards the target analyte.

One analyte that demands attention is the sensing of lead(II) ions which continues to be one of the most problematic toxic heavy metals that has caused environmental contamination and health problems around the world. ${ }^{1-3}$ It acts as a cumulative toxicant that affects different body systems including the neurological, haematological, gastrointestinal, cardiovascular and renal systems. Children are particularly vulnerable to the neurotoxic effects of lead, even at even relatively low levels of exposure, potentially causing serious and irreversible neurological damage. ${ }^{1,3}$ As a result of its negative

Faculty of Science and Engineering, School of Science and the Environment, Division of Chemistry and Environmental Science, Manchester Metropolitan University, Chester Street, Manchester M1 5GD, UK. E-mail: c.banks@mmu.ac.uk; http://www. craigbanksresearch.com; Fax: +44 (0)161-247-6831; Tel: +44 (0)161-247-1196 $\dagger$ Electronic supplementary information (ESI) available. See DOI: 10.1039/ c5an01218j health affects, lead(II) ions are regulated by the World Health Organisation (WHO) to a maximum of $10 \mathrm{ppb}(48.26 \mathrm{nM})$ within drinking water ${ }^{4}$ mirrored by the United States Environmental Protection Agency (EPA) which states no higher than 15 ppb (72.39 nM) in drinking water. ${ }^{5}$ Clearly, there is a need for the on-site detection of lead(II) ions using portable, inexpensive and sensitive analytical methods - electrochemical techniques provide a potential solution. In the literature there are various attempts at the electrochemical quantification of lead(II) ions ${ }^{2,6-14}$ such as DNA electrodes, ${ }^{6}$ carbon nanotubes, ${ }^{8}$ carbon ionic liquid electrodes, ${ }^{9}$ screen-printed sensors ${ }^{12}$ and reduced graphene oxide modified screen-printed sensors. ${ }^{14}$

In this communication, it is demonstrated for the first time, that British coinage, namely a 5 pence (GBP) coin, can be used as a novel electrical substrate. For this new branch of electrochemistry the phrase "Regal electrochemistry" has been coined. Through the use of information readily available from the Royal mint website ${ }^{15}$ the composition of the current coins in circulation is known and presented in Table $1 .{ }^{15}$ The British 5 pence (GBP) coin offers the potential to be a low cost electrochemical sensing platform that is reproducible and particu-

Table 1 Composition of coins currently in circulation in the United Kingdom, ${ }^{15}$ text in bold indicates the coinage used in this work

\section{Coin Composition}

1p Bronze (97\% copper, 2.5\% zinc, 0.5\% tin) - until September 1992 Copper-plated steel - since September 1992

2p Bronze (97\% copper, 2.5\% zinc, 0.5\% tin) - until September 1992 Copper-plated steel - since September 1992

5p Pre-2012 copper-nickel (cupro-nickel alloy) 75\% copper, 25\% nickel Post-2012 Nickel-plated steel - since January 2012

20p Pre-2012 copper-nickel (cupro-nickel alloy) 75\% copper, 25\% nickel Nickel-plated steel - since January 2012

50p Cupro-nickel (84\% copper, 16\% nickel)

$£ 1$ Cupro-nickel (75\% copper, $25 \%$ nickel)

$£ 2$ Outer: nickel-brass (76\% copper, $4 \%$ nickel, $20 \%$ zinc) Inner: cupro-nickel (75\% copper, $25 \%$ nickel) 
larly useful as the coin is two sided, placing its value at just 2.5 pence per sensor. This is primarily useful when the electroanalytical protocol is intended to be implemented into third world countries where the realisation of low cost, reliable sensors is imperative to applications such as heavy metals testing nevertheless, there is no reason to suggest that 'Regal' electrochemical sensors cannot be 'coined' for other analytical applications.

\section{Results and discussion}

British coinage was obtained and treated as described in the experimental section (see ESI $\dagger$ ) with which to test the theory that coins can be potentially utilised as novel electrode substrates; to the best of our knowledge, there are no reports using coins as electrochemical substrates. To test the coins electrochemical reactivity towards the detection of lead(II) ions, two coins, held within a bespoke Polytetrafluoroethylene (PTFE) 'housing unit' (see ESI Fig. 1†), were subject to 'electrolysis' to allow the ions to deposit on the surface. To this end, the two coins were independently held at a suitable negative potential $(-1.2 \mathrm{~V})$ in an aqueous $\mathrm{pH} 4$ acetate buffer solution containing $1000 \mathrm{nM} \mathrm{Pb(II)} \mathrm{(lead(II)} \mathrm{nitrite)} \mathrm{to} \mathrm{allow} \mathrm{the} \mathrm{depo-}$ sition of lead, in the form of lead metal, onto the coins surface to occur. Fig. 1 shows scanning electron microscope (SEM) images of the two coins before and after deposition. Note: Scanning Electron Microscope - Energy-Dispersive X-ray microanalysis (SEM-EDX) was employed as confirmatory analysis to demonstrate the coins contained no impurities and to show if lead was present on the surface following electrodeposition. It was also utilised to confirm the sheet nickel metal used (see later) was pure nickel. Discernible from Fig. 1 is that the deposition of metallic lead shows a much higher affinity of adsorption on the $5 \mathrm{p}$ coin minted post-2012 (Fig. 1(ii)B) opposed to the surface of coins minted prior to 2012 (Fig. 1(ii)A). As previously mentioned, in information readily available from the United Kingdom's Royal Mint, the composition of a 5p coin since January 2012 has been nickel plated steel and prior to this date it was a copper-nickel alloy (cupro-nickel); see Table 1. This suggests, as it is present in both, lead(II) binds to the nickel present in the coins/upon the coins surface. A secondary result of this is; as the lead is actively deposited on nickel this technique could be used for mapping nickel-based alloys in light of its selectivity towards nickel over other metals.

i)

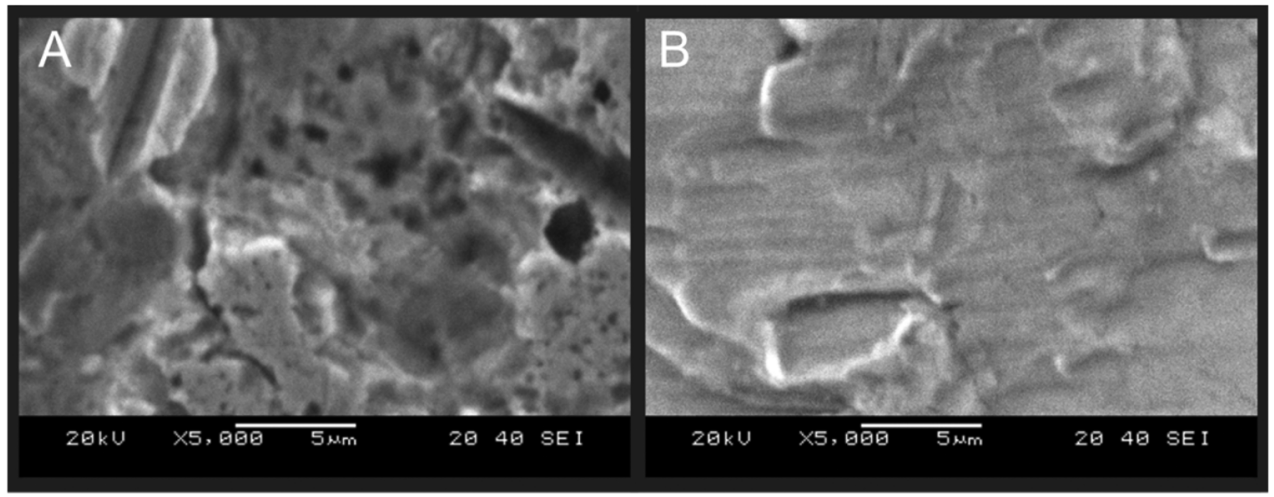

ii)

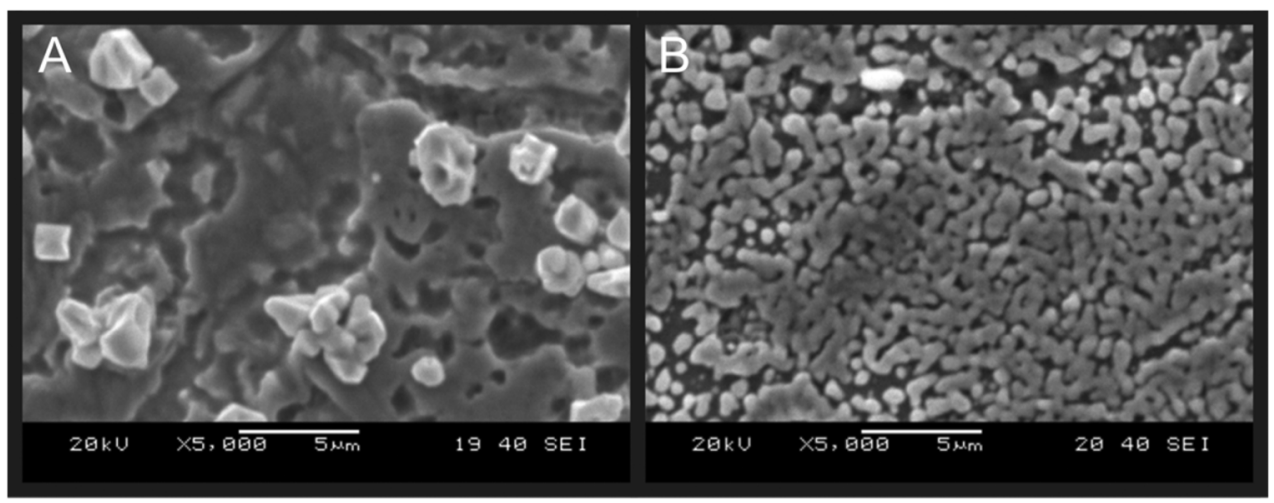

Fig. 1 (i) SEM micrographs of British 5 pence coins minted A: pre-2012 (cupro-nickel alloy 75\% copper, 25\% nickel) and B: post-2012 (nickel-plated steel). (ii) SEM micrographs following the desposition of lead(II) on British 5 pence coins minted A: pre-2012 (cupro-nickel alloy $75 \%$ copper, $25 \%$ nickel) and B: post-2012. (nickel-plated steel). 
In light of its higher nickel content (and therefore higher affinity for lead deposition) the electrochemical performance of the post-2012 5 pence (5p) coin electrode (held in the custom-made PTFE 'housing unit'; see ESI Fig. 1†) was explored first using the outer-sphere redox probe $1 \mathrm{mM}$ hexaammineruthenium(III) chloride/0.1 $\mathrm{M} \mathrm{KCl}$ over the scan rate range 5-200 $\mathrm{mV} \mathrm{s}^{-1}$. Fig. 2 shows the obtained voltammetric response and clearly observable is the process of electron transfer wherein a reduction process occurs at approximately $-0.25 \mathrm{~V}$ and an oxidation process at $-0.1 \mathrm{~V}$ : this is indicative of the potential use of a $5 p$ coin as an electrochemical substrate. A pre-2012 5p coin was also tested in $1 \mathrm{mM}$ hexaammineruthenium(III) chloride/0.1 M KCL and is found to yield a poor electrochemical response (ESI Fig. $2 \dagger$ ). A large cathodic wave is observed at $\sim-0.2 \mathrm{~V}$ using the pre-2012 $5 \mathrm{p}$ coin which is similar to that reported for copper reduction as previously reported in the literature. ${ }^{16}$ Coins minted pre-2012 have a large composition of copper $(75 \%)$ that is, mostly likely, in the form of an oxide such as $\mathrm{Cu}_{2} \mathrm{O}$ or $\mathrm{CuO}$. In light of the composition, the following processes likely occur:

$$
\mathrm{Cu}_{(\mathrm{aq})}{ }^{2+}+2 \mathrm{e}^{-}(\mathrm{m}) \rightleftharpoons \mathrm{Cu}_{(\mathrm{s})}
$$

Or

$$
\mathrm{Cu}_{(\mathrm{aq})}{ }^{+}+\mathrm{e}_{(\mathrm{s})}^{-} \rightleftharpoons \mathrm{Cu}_{(\mathrm{s})}
$$

From this it can be readily deduced that the electrochemical reduction of copper will dominate the electrochemical response as opposed to the desirable reduction of lead(II) on pre-2012 5p coins (as is evident from Fig. 1) and as such, all experiments performed were with the use of a coin minted post-2012.

A control experiment was performed using a possible alternative to the potential coin electrodes. Visible in ESI Fig. $3, \dagger$ confirmation of nickel's electroactivity towards lead(II)

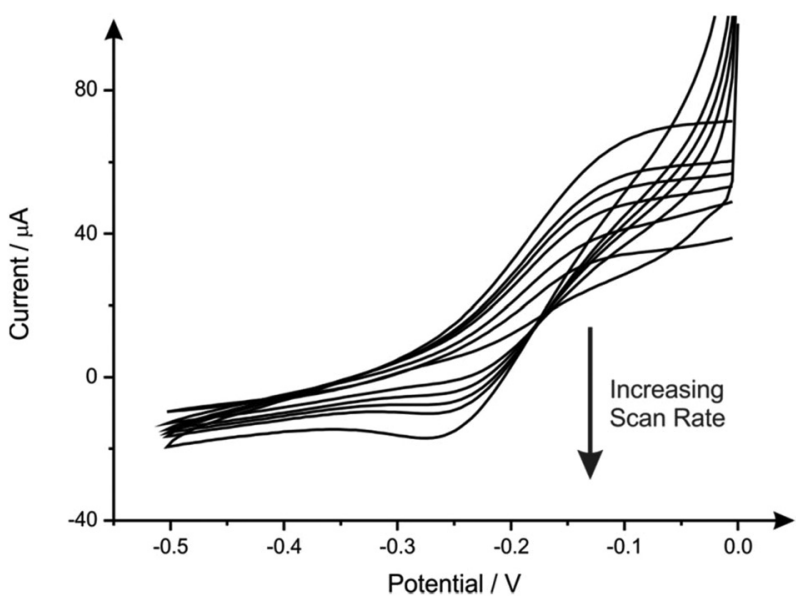

Fig. 2 Cyclic voltammetry scan rate study recorded at 5, 10, 25, 50, 75, 100 and $200 \mathrm{mV} \mathrm{s}^{-1}$ (vs. SCE) using $5 \mathrm{p}$ british coin (2012) in $1 \mathrm{mM}$ hexaammineruthenium(III) chloride in $0.1 \mathrm{M}$ potassium chloride. by using pure nickel sheet metal (contained within the PTFE 'housing unit') towards a $48.3 \mathrm{nM}$ solution of lead(II). Whilst there is a measurable response, it comes with a much greater financial outlay $(25 \mathrm{~mm} \times 25 \mathrm{~mm}$ sheets can have costs in excess of $£ 100$ (ref. 17)) and it is not as prevalent as the readily available 5 pence coin. Regal electrochemistry is also beneficial when compared to using nickel plated metal which have been used as electrode substrates ${ }^{18}$ as the plating can be a long process and not everybody has access to the specialist equipment required to perform such techniques however, everybody in the United Kingdom has access to low denominations of its currency.

Having determined that 5p coins minted post-2012 offered the best sensor apropos of lead ion determination its electroanalytical performance was explored. A series of additions were made over the analytical range 5-1000 $\mathrm{nM}$ into a $\mathrm{pH} 4$ acetate buffer solution; the square wave voltammograms obtained utilizing the 5 p-coin through the additions of lead are illustrated in Fig. 3. Note that at high concentrations the electrode surface is likely saturated accounting for the plateau observed in the insert of Fig. 3 and the additional pre-peak. Analysis of the calibration curves (Fig. 3 inset), constructed using the oxidation peak at approximately $-0.40 \mathrm{~V}$ reveal a limit of detection $(3 \sigma)$ equal to $1.97 \mathrm{nM}$ which is within the WHO guidelines of $10 \mathrm{ppb}(48.26 \mathrm{nM})$ in drinking water. ${ }^{1,4}$ In light of this, the presented avant-garde, proof-of-concept 'Regal electrochemistry' square-wave voltammetric approach is a much cheaper, facile method for the detection of lead as opposed to other key advancements within the area. ${ }^{19-21}$ Note that faces

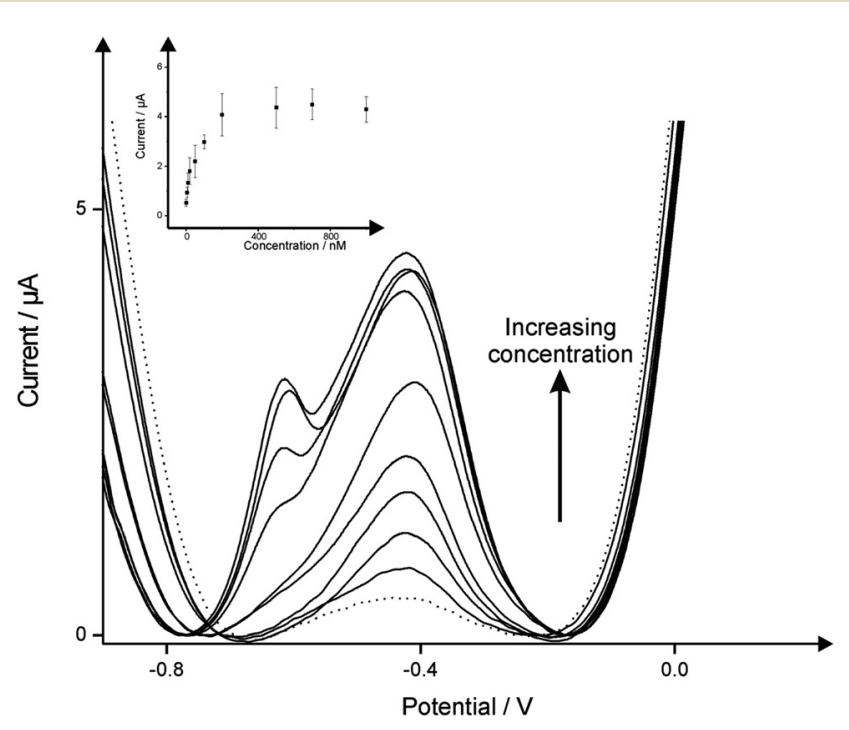

Fig. 3 Square-wave voltammetry showing the response resulting from the additions of $5 \mathrm{nM}-1000 \mathrm{nM}$ lead(II) in a pH 4 acetate buffer solution. Dotted line represents blank $\mathrm{pH} 4$ acetate buffer solution. Note: visible peak in the blank is likely due to contamination of lead(II), a common issue associated with trace analysis. Inset: A typical calibration plot corresponding to addition of lead over the range $0 \mathrm{nM}-1000 \mathrm{nM}$ using $5 p$ British (2012). The responses shown are an average response with corresponding errors bars $(N=3)$. 
on the coins have reliefs. In our experiments both sides of the coin are utilised; ESI Fig. $4 \dagger$ shows the two sides of the coinage used in this work. This potentially adds to the surface "roughness" however, this is negligible since on the timescale of the experiment the diffusion layer is larger than the "roughness". Note that both sides of coins have been used and used to provide error bars presented in the inset of Fig. 3 .

In summary we have demonstrated that coinage can be successful utilised as electrode sensor. Further work will see other coins explored electrochemically for their response to an array of analytes to advance the area of Regal electrochemistry.

\section{Conclusions}

Proof-of-concept that British coinage can be successfully utilised as a useful electrode material has been shown with detection of lead in the nM range with model solutions. This has been compared to high quality (pure) nickel sheet metal and due to its significant cost has no advantages over the use of coinage as an electrode material - the use of a 5 pence incurs the cost of just 2.5 pence since both sides can be readily utilised. Note that the use of coinage as an electrode material is an attractive proposition since everyone will have a coin in his or her pocket, which can be readily utilised at low cost with minimal pretreatment and in light of its low cost can be used as a one shot sensor. This is particularly useful in both developing countries and emergency cases such as those postured in militaristic applications. From inspection of Table 1 , one can readily see that other coins have favorable compositions that could also be potentially used as electrode substrates. The concept of Regal electrochemistry can be expanded to other coinage towards a range of target (electroactive) analytes; such work is currently underway.

\section{References}

1 World Health Organization, International Programme on Chemical Safety: Lead, http://www.who.int/ipcs/assessment/ public_health/lead/en/, accessed April 2015.

2 W. Yantasee, Y. Lin, K. Hongsirikarn, G. E. Fryxell, R. Addleman and C. Timchalk, Environ. Health Perspect., 2007, 115, 1683-1690.
3 R. A. Goyer, Toxicology of metals - biochemical aspects, Springer-Verlag, New York, 1995.

4 WHO, Guidance for Drinking Water Quality, Recommendations, Geneva, 2nd edn, 1993, vol. 1.

5 United States Environmental Protection Agency, Safe Water Drinking Act: Levels of Copper and Lead, http://water.epa. gov/lawsregs/rulesregs/sdwa/lcr/index.cfm, accessed June 2015.

6 Y. Xiao, A. A. Rowe and K. W. Plaxco, J. Am. Chem. Soc., 2007, 129, 262-263.

7 G. Mai, L. Xia and W. Wang, Russ. J. Electrochem., 2013, 49, 447-452.

8 Y. Zhu, G.-m. Zeng, Y. Zhang, L. Tang, J. Chen, M. Cheng, L.-h. Zhang, L. He, Y. Guo, X.-x. He, M.-y. Lai and Y.-b. He, Analyst, 2014, 139, 5014-5020.

9 H.-J. Liu, L.-N. Qu, S. Hu, T.-R. Zhan, C.-Z. Zhao and W. Sun, J. Chin. Chem. Soc., 2010, 57, 1367-1373.

10 A. Wanekaya and O. A. Sadik, J. Electroanal. Chem., 2002, 537, 135-143.

11 I. V. Anambiga, V. Suganthan, N. A. N. Raj and A. S. Kumar, Electrochemical sensor for the detection of lead ions, 2013.

12 A. Mandil, L. Idrissi and A. Amine, Microchim. Acta, 2010, 170, 299-305.

13 A. P. Ruas de Souza, C. W. Foster, A. V. Kolliopoulos, M. Bertotti and C. E. Banks, Analyst, 2015, 140, 4130-4136.

14 J.-M. Jian, Y.-Y. Liu, Y.-L. Zhang, X.-S. Guo and Q. Cai, Sensors, 2013, 13, 13063-13075.

15 The Royal Mint, Coin Design and Specifications: Five Pence Coin, http://www.royalmint.com/discover/uk-coins/coin-designand-specifications/five-pence-coin, accessed April 2015.

16 D. Stankovic, G. Roglic, J. Mutic, I. Andjelkovic, M. Markovic and D. Manojlovic, Int. J. Electrochem. Sci., 2011, 6, 5617.

17 Goodfellow Supplier of Materials for Research and Development, http:/www.goodfellow.com/E/Nickel-Foil.html, accessed July 2015.

18 P. Y. Chen, H. H. Yangi, J. M. Zen and Y. Shih, J. AOAC Int., 2011, 94, 1585-1591.

19 B. Chen, Z. Wang, D. Hu, Q. Ma, L. Huang, C. Xv, Z. Guo and X. Jiang, Sens. Actuators, B, 2014, 200, 310-316.

20 G. Lisak, J. Bobacka and A. Lewenstam, J. Solid State Electrochem., 2012, 16, 2983-2991.

21 E. Kirowa-Eisner, M. Brand and D. Tzur, Anal. Chim. Acta, 1999, 385, 325-335. 